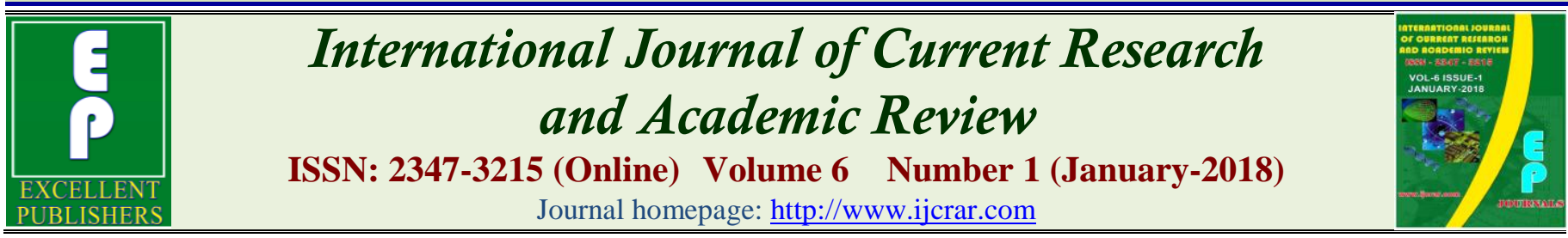

doi: https://doi.org/10.20546/ijcrar.2018.601.007

\title{
Interpersonal Relationship Skill of Staff Nurses
}

\author{
C. V. Sheeja ${ }^{1 *}$ and K. Reddemma ${ }^{2}$ \\ ${ }^{1}$ MIMS College of Nursing, Vazhayoor, Puthukode PO, Ramanattukara-673633, India \\ ${ }^{2}$ National Consortium for PhD in Nursing, INC, St. John's College of Nursing, Sarjapur Road, Bengaluru- 560034, \\ Karnataka, India \\ *Corresponding author
}

\section{Abstract}

The success of nurses in delivering the patient care are depend on with their Interpersonal Relationship Skills. Nurses are the core member in the health care team. Nurses are able to provide the quality patient care through their therapeutic relationship. Nurses should be skilled in their soft skills. Their soft skills can be measured through the IPR Skills Scale. This study has been undertaken in an attempt to assess the Interpersonal Relationship Skills of staff nurses working in the hospitals. Assess the Interpersonal Relationship Skills of staff nurses working in the hospitals. A quantitative approach to assess the Interpersonal Relationship Skills of staff nurses with a descriptive design was adopted in the study. Non- Probability method through simple random sampling technique and IPR Skills Scale was used to collect data from staff nurses working in hospitals at Bangalore. Staff nurses are having an average Interpersonal Relationship Skills. Staff nurses have more involvement in working as a team member and comprehensive approach while caring for their patients. Team work and comprehension have scored the highest in the Interpersonal Relationship Skills. Soft skills for the nurses are basis of providing the nursing care to their patients. Nurses with good interpersonal relationship skills are needed in the health care delivery system. Results of this present study demonstrate that staff nurses have an average Interpersonal Relationship Skills. Findings suggest that Nurse Administrators should make efforts that are needed to improve the Interpersonal Relationship Skills of staff nurses for a positive ambience in their workplaces.
\end{abstract}

\section{Introduction}

Human beings are innately social and are shaped by their experiences with others. Interpersonal relationship is an interaction between two or more people. Attraction between individuals brings them close to each other and

\section{Article Info}

Accepted: 31 December 2017

Available Online: 20 January 2018

\section{Keywords}

IPR= Interpersonal Relationship Skills 
The ability to communicate effectively with superiors, colleagues, and staff is essential for the nurses to work effectively with others. A good communicator is always a good listener. Active listening involves paying close attention to what their customers are saying, asking clarifying questions, and rephrasing what the nurses say to ensure the understanding.

Nonverbal Communication is the gestures used by the nurses to communicate with others and it accounted for 55 percent of the Nurses' communication. A relaxed, and a friendly tone for the nurses will make to appear approachable, and will encourage others to speak openly. Exuding confidence can be as simple as making eye contact or using a firm but in friendly tone. ${ }^{1}$

Think before saying anything will help to avoid talking excessively and confusing others. A good communicator should enter any conversation with a flexible and an open mind. It is important to be open to listening which helps to understand the other person's point of view. Give and receive feedback is an important communication skill for the Nurses. The way messages were sent, especially their clarity, and a leadership style was the highest importance when HR managers wanted to enhance employee commitment to the organization. ${ }^{2}$

Both qualitative and quantitative communication studies of recent years consistently determined that many organizations evaluated communication competence and skills as the most significant factor for cultivating human relationships in addition to improving job performance, productivity, and group cohesion ${ }^{3-5}$.

Human relations are basic to human interaction and essential for nursing practice. Interpersonal relationship skills are most frequently used in nursing situations and lies at the heart of nursing practice.

Therapeutic interpersonal relationships have the capacity to transform and enrich the patients' experiences. ${ }^{6}$ Management interventions may be instrumental in promoting friendships at work, by initiating social activities both inside and outside of the workplace. Nurses need to get along well with their coworkers for a positive ambience in workplaces and also for healthy interpersonal relationship ${ }^{7}$.

\section{Materials and Methods}

This study used a quantitative approach with a descriptive design to measure the Interpersonal Relationship Skill of the staff nurses.

\section{Population}

All nurses working in three hospitals in Bangalore during the time of data collection were comprised the population of the study.

\section{Sample and setting}

In this cross-sectional study, Convenient sampling was used to select the government, corporate and mission hospitals and Simple random sampling was used in selecting the sixty staff nurses from each hospitals $(\mathrm{N}=180)$.

\section{Measure}

The instrument used for the study was Interpersonal Relationship Skill Scale consists of 60 items, self-report measure developed by the researcher to assess clinically relevant interpersonal relationship skills. The items were chosen within the dimensions of IPR, (a) Listening Skills, (b) Effective Speaking, (c) Motivation, (d) Self Concept, (e) Assertiveness, (f) Negotiation Skills, (g) Critical Thinking, (h) Conflict Resolution, (i) problem Solving, (j) Team Work, (k) Coping Skills, and (l) Comprehension.

The participants are asked to indicate how often the items apply to themselves, with response ranging from 0 4 , where 0 is almost never, 1 is rarely, 2 is sometimes, 3 is most often, and 4 is almost always.

The items were recorded so that the higher the score in every case indicated higher the interpersonal relationship skills. Sample items include "I keep thinking about the words used in the conversation while listening", "I avoid the people to whom I have the hurt feeling" were reversed score.

Content validity of the measure was determined by doing the Content Validity Index. Nine experts in the field of Nursing and Psychology were rated the instrument on a 4-point scale and the percentage of total items rated by the experts, CVI score is.97. Test -retest reliability of the tool established with thirty staff nurse with one week gap, $\mathrm{r}=.838$.

\section{Procedures}

After acquiring Institutional Review Board approvals from each hospital, permission of the hospital authorities in the three hospitals were obtained prior to the data 
collection. Written consent was obtained from individual participants. The data was collected for a period from 0201-15 to 30-03-15. The obtained data was analyzed using descriptive and inferential statistics.

\section{Results and Discussion}

The Interpersonal Relationship Skill of staff nurses were categorized in the sub-dimensions of Listening Skills, Effective Speaking, Motivation, Self -Concept, Assertiveness, Negotiation Skills, Critical Thinking, Conflict Resolution, Problem Solving, Team Work, Coping Skills, and Comprehension. Each item in the scale was scored for $0-4$.

The staff Nurses scored each sub-dimensions above the average score which indicate that the staff nurses have above average Interpersonal Relationship Skill.

Figure-1 shows that the mean and SD of the Interpersonal Relationship Skills of staff nurses working in the hospital. Self-Concept and Assertiveness of the staff nurses were comparatively less scored. The sub dimensions of Team Work and Comprehensive approach have scored (above 2.5 score) $2.54 \pm 0.50$ and $2.64 \pm 0.65$ respectively.

Results from the present study revealed that soft skills are very important in the nursing profession. Maintaing the therapeutic relationship is required for the nurses. The success of quality based patient care given by the nurses are relied on their soft skills. The staff nurse have average Interpersonal Relationship Skill working in the hospitals. The ability to work with team is good for the staff nurses.

A similar study results shows that communication control used by hospice interdisciplinary team members to share information and contribute to decision making in team meetings are the relationship communication. Providers should examine the potential effect of interpersonal communication in team meetings. ${ }^{8}$

Table.1 Interpersonal Relationship Skill level of staff nurses (Mean \& SD)

\begin{tabular}{|l|c|c|}
\hline Category & Average IPR & Std. Deviation \\
\hline Listening Skill & 2.49 & 0.49 \\
\hline Effective Speaking & 2.25 & 0.37 \\
\hline Motivation & 2.34 & $\mathbf{0 . 5 5}$ \\
\hline Self-Concept & 2.10 & $\mathbf{0 . 4 0}$ \\
\hline Assertiveness & 2.12 & $\mathbf{0 . 4 0}$ \\
\hline Negotiation Skill & $\mathbf{2 . 4 0}$ & $\mathbf{0 . 5 1}$ \\
\hline Critical Thinking & 2.25 & $\mathbf{0 . 5 2}$ \\
\hline Conflict Resolution & 2.25 & $\mathbf{0 . 4 7}$ \\
\hline Solving Problem & 2.20 & $\mathbf{0 . 4 6}$ \\
\hline Team Work & 2.54 & $\mathbf{0 . 5 0}$ \\
\hline Coping Skills & 2.36 & $\mathbf{0 . 5 0}$ \\
\hline Comprehension & 2.64 & $\mathbf{0 . 6 5}$ \\
\hline
\end{tabular}

Fig.1 Interpersonal Relationship Skill level of staff nurses

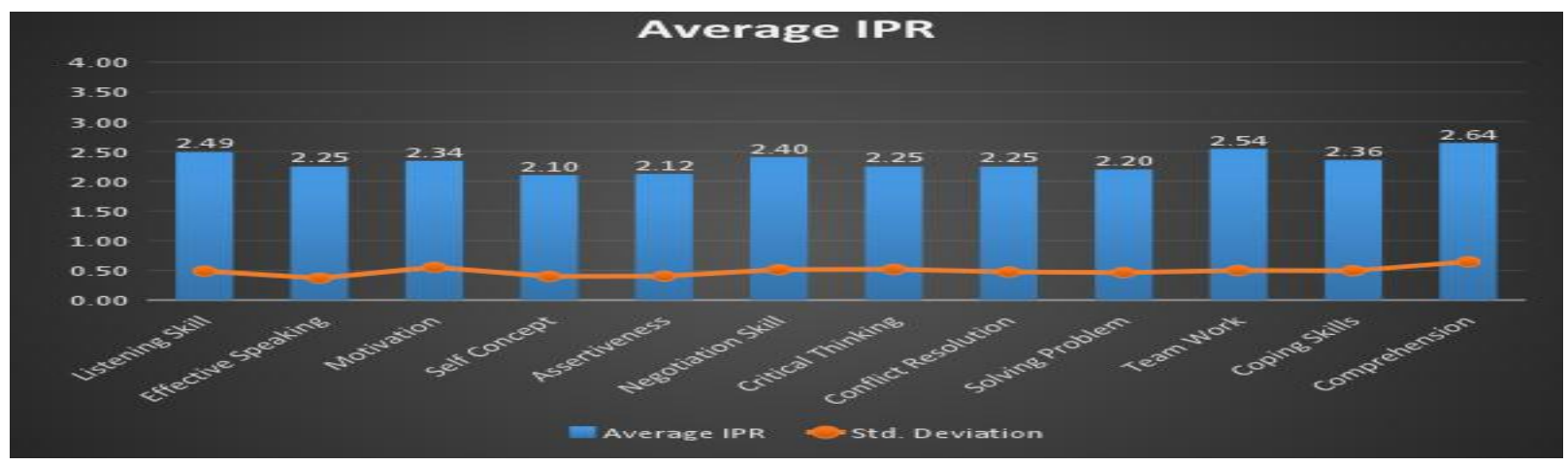


An observational study confirm that majority of nurse patient interactions were superficial, routinized and related to task. It was found that nurses extent a lot of control over interactions. Examinations of interactions also reveals, issues of conflicts arising from the caring and controlling functions that nurses perform. ${ }^{9}$ Findings suggests more attention should be given in developing Interpersonal Relationship skills within the profession. Interpersonal relationship programs have positive effects for improving interpersonal skills of staff nurses.

\section{Implications}

Nurses are knowledge workers. Improving the soft skills of the nurses are very important. Retaining the skilled nurses in their organization is the challenge of the nurse administrators. Hence the Organizations should use measures to improve the Interpersonal Relationship Skill of staff Nurses.

Interpersonal relationship skills are a set of abilities enabling the nurses to interact and communicate positively, confidently, and work effectively with others, and the ability to listen and understand, the problem solving, decision making, assertiveness, negotiating and personal stress management. Strong Interpersonal relationship skills create more satisfying interaction in all environments. Developing people's skills involves building strong relationship, demonstrating ethical behavior, communicating and working effectively in teams.

\section{References}

1. Adigwe $\mathrm{P}$ and Okoro E, Human Communication and Effective Interpersonal Relationships: An

\section{How to cite this article:}

Sheeja C. V. and Reddemma K. 2018. Interpersonal Relationship Skill of Staff Nurses. Int.J.Curr.Res.Aca.Rev. 6(1), 40-43. doi: https://doi.org/10.20546/ijcrar.2018.601.007
Analysis of Client Counseling and Emotional Stability, International Journal of Economics \& Management Sciences, 5:336. doi:10.4172/21626359.1000336.

2. Alistar H (1995) "Nurses power in interaction with patients". Journal of Advanced Nursing, Jan Vol 21(1). Pp 75.82.

3. Bambacas M, Patrickson M, (2008) "Interpersonal communication skills that enhance organisational commitment", Journal of Communication Management, Vol. 12 Issue: 1, pp.51-72, https://doi.org/10.1108/13632540810854235

4. Gladstein GA (1974) Nonverbal communication and counseling psychotherapy: A review. Counseling Psychologist.

5. Hughey AR (1974) Nonverbal behaviors, their use in counseling and implications for counselor education. Dissertation Abstracts International 35: 189-190.

6. Kornhaber R, Walsh K, Duff J, and Walker K, (2016) Enhancing adult therapeutic interpersonal relationships in the acute health care setting: an integrative review, J Multidiscip Healthc. 2016; 9: 537-546, 2016 Oct $14 . \quad$ doi: 10.2147/JMDH.S116957.

7. Mehrabian A (1972) Nonverbal communication. Chicago: Aldine-Atherton.

8. Patricia O, (2015) Improving Interpersonal Relationship in Workplaces, IOSR Journal of Research \& Method in Education (IOSR-JRME), eISSN: 2320-7388,p-ISSN: 2320-737X Volume 5, Issue 6 Ver. II (Nov. - Dec. 2015), PP 115-125.

9. Wittenberg E, Demiris P G, (2009) Exploring interpersonal communication in hospice interdisciplinary team meetings, Journal of Gerontological Nursing, Vol. 35, No. 7, Pg.38-45. 